\title{
STUDI KASUS TINGKAT INFEKSI CACING PADA PETERNAKAN KAMBING BOER DI KABUPATEN BANYUMAS
}

\author{
Case Study of Worm Infection in Boer Goats Farm in Banyumas District \\ Mohandas Indradji, Endro Yuwono, Diana Indrasanti, Muhamad Samsi, Sufiriyanto, \\ Asep Herlan R., Budi Herdiana \\ Faculty of Animal Husbandry Universitas Jenderal Soedirman \\ Karangwangkal, North Purwokerto, Banyumas Regency, Central Java 53123 \\ E-mail : mohandas.indradji@gmail.com
}

\begin{abstract}
The worm infections can cause a decrease in livestock productivity, were in the form of a decrease in body weight, milk production, growth restriction, decrease immunity to disease, even death. Research on worm disease in Boer goats aims to determine the infection rate of Nematodiasis and Trematodiasis in goats with various age levels, young and adult age groups. This research method is survey with sampling technique is sampling by the judgment. The data analysis of the research was prevalence study and Chi-Square analysis (X2). The examination of worm eggs in feces on the research used centrifuge method. The results of examination on 30 samples of Boer goats showed that $93.33 \%$ of Boer goats were infected by Nematodes and $13.33 \%$ of Boer goats were infected by Trematoda. Infection rates of Nematodes and Trematoda were not showed any significant differences between the two groups. The low level of Trematodiasis in Boer goats indicates that Boer goats in Banyumas district are resistant to Trematoda worm infections.
\end{abstract}

Keywords: Boer Goats, Centrifuge Method, Chi-Square Analysis, Infection Rate, Worm Infection

\section{PENDAHULUAN}

Peternakan kambing Boer di Kabupaten Banyumas merupakan rintisan dan hanya ditemukan di satu tempat, yaitu di Desa Karangtengah, Kecamatan Baturaden. Usaha peternakan kambing Boer ini dilakukan sebagai usaha sambilan, namun demikian dalam tata laksana pemeliharaannya dilakukan dengan cara beternak yang modern. Usaha peternakan tersebut melibatkan tenaga profesional di bidangnya, tenaga kerja yang dimiliki oleh peternakan tersebut, diantaranya terdapat ahli pembibitan, ahli nutrisi, dan memiliki sistem perkandangan dan padang rumput yang rapi dan terpelihara dengan baik. Usaha peternakan tersebut dinilai telah melakukan manajemen peternakan yang lebih maju dibandingkan dengan peternakan rakyat disekitarnya serta telah menerapkan beberapa kiat yang dianjurkan dalam usaha peternakan yang baik. Kambing Boer yang dipelihara dalam peternakan ini digunakan untuk dimanfaatkan sebagai ternak penghasil daging. Bibit kambing diperoleh dari impor, sebagai produk usaha peternakan berupa keturunan F1 hasil dari mengawinkan pejantan kambing Boer dengan betina kambing PE, yang dijual sebagai ternak pedaging.

Beberapa waktu yang lalu, dalam rentang satu tahun pemeliharaan, peternak melaporkan banyak kematian yang tinggi pada kelompok ternak dengan gejala penyakit yang menonjol adalah penyakit yang menyerang sistem pencernaan dengan anoreksia, kekurusan, diare dan berakhir dengan kematian, sehingga menimbulkan kerugian ekonomi yang cukup signifikan.

Pada diagnosis secara fisik/klinis, peneliti menduga bahwa kelompok kambing Boer terinfeksi penyakit cacing, kemudian peneliti melakukan investigasi lebih lanjut pada peternakan tersebut untuk mengungkap peyebab atau faktorfaktor yang bisa berakibat pada sakit dan kematian kambing di peternakan tersebut untuk mendapatkan solusi atas persoalan yang dapat teridentifikasi.

\section{MATERI DAN METODE}

Materi berupa 30 sampel feses kambing Boer (50\% dari populasi yang ada). Sampel yang 
diambil telah ditetapkan dalam tiga kategori umur yaitu : 1) Kambing yang sedang menyusui, 2) Kambing yang sudah lepas sapih dan 3) Kambing yang sudah dewasa. Sampel tidak dibedakan antara kambing jantan dan betina, karena jenis kelamin bukan merupakan pembeda dalam mekanisme infeksi penyakit cacing.

Metode yang digunakan yaitu survei infeksi cacing dengan melakukan pemeriksaan mikroskopik telur cacing pada sampel feses kambing Boer pada berbagai kategori umur. Variabel yang diamati adalah telur cacing Nematoda dan Trematoda gastrointestinal. Penetapan sampel dilakukan dengan metode sampling by the judgment (50\% dari populasi). Metode pemeriksaan telur cacing dilakukan pengamatan secara kualitatif dengan metode Apung/Sentrifus (Soulsby,1982).

Analisis deskriptif digunakan untuk menentukan jenis/spesies cacing melalui pengamatan mikroskopis. Tingkat infeksi cacing pada kambing dihitung dengan rumus (Naseh, 1993) yaitu :

\section{Tingkat Infeksi \\ $=\underline{\text { Jumlah ternak yang terinfeksi }} \times 100 \%$ Jumlah ternak sampel}

Analisis Chi-Kuadrat (Chi-Square) digunakan untuk menyatakan kekuatan hubungan antara tingkat infeksi cacing pada berbagai kategori umur ternak kambing Boer (Djuniadi et al., 2016).

\section{HASIL DAN PEMBAHASAN}

Desa Karangtengah mempunyai suhu ratarata harian $27^{\circ} \mathrm{C}$, kelembaban rata-rata harian $90 \%$, curah hujan rata-rata pertahun $2000 \mathrm{~mm}^{3}$, ketinggian tempat $175-200 \mathrm{~m}$ di atas permukaan laut. Gambaran geografis yang menonjol dan kurang mendukung dalam pemeliharaan kambing boer adalah bahwa desa tersebut mempunyai kelembaban yang tinggi dan curah hujan yang tinggi, karena kondisi ini sangat berbeda dengan dengan kondisi asal dari ternak tersebut yang bersuhu tinggi dan kelembaban rendah/kering di daerah Afrika, khususnya Afrika Selatan. Sementara itu kondisi cuaca di daerah tersebut sangat mendukung bagi pertumbuhan telur dan larva cacing parasit pada tanaman rumput. Menurut Indradji dan Yuwono (2004), tanaman rumput di padang penggembalaan sangat berpengaruh nyata dalam pola infeksi penyakit cacing di Indonesia, dan menurut Prastowo dan Sumartono(1996) bahwa rumput dan air minum yang tercemar larva cacing merupakan perantara dalam infeksi cacing ke tubuh ternak.

Pada peternakan tersebut, kambing dipelihara di dalam kandang secara terus menerus dan tidak digembalakan. Pakan yang diberikan berupa hijauan dengan frekuensi pemberian tiga kali sehari pada pagi, siang dan sore. Hijauan yang diberikan berupa rumput odot (Pennisetum purpureum cv Mott), konsentrat berupa dedak atau ampas tahu. Pemberian air minum dilakukan secara adlibitum yang berasal dari sumber mata air. Kandang kambing berbentuk panggung dengan alas slat yang terbuat dari kayu. Menurut Rianto (2004), pembersihan feses rutin pada kandang panggung dapat mengurangi kuman penyakit, parasit dan jamur berkembang biak. Menurut Indradji dan Yuwono(2004) tipe kandang panggung pada ternak kambing tidak memberikan hasil yang berbeda nyata dibandingkan dengan tipe kandang lemprakkan terhadap kejadian infeksi cacing Nematoda. Jadi kandang panggung lebih berpengaruh pada penampilan kebersihan, dengan kondisi alas yang lebih kering dibandingkan dengan kandang lemprakkan, tetapi sisi kekurangannya memerlukan biaya yang lebih banyak untuk pengadaannya.

Peneliti tidak membahas tingkat infeksi cacing Cestoda pada naskah ini, karena jika terjadi infeksi cestoda pada ternak kambing, tanda-tanda pada feses akan terlihat dengan kasat mata yaitu dengan ditemukannya segmen atau proglotid cacing pada feses kambing dan peternak juga tidak pernah melaporkan adanya temuan tersebut. Jadi peneliti hanya membahas tingkat ingeksi cacing Nematoda dan Trematoda.

Hasil pemeriksaan pada 30 sampel feses kambing Boer menunjukkan bahwa 28 ekor kambing terinfeksi cacing Nematoda dengan persentase 93,33\% dan hanya 2 ekor yang negatif $(6,67 \%)$, dengan jenis cacingnya Strogyle sp. dan Capillaria sp. Empat ekor kambing $(13,33 \%)$ terinfeksi cacing trematoda dan 26 ekor $(86,67 \%)$ negatif, jenis cacing trematoda spesies cacing yang teridentifikasi adalah Fasciola sp. Tingkat infeksi cacing nematoda pada kasus ini termasuk sangat tinggi jika dibandingkan dengan penelitian Mukti et al. (2016) yang di Kabupaten Banyuwangi. Perbedaan ini diduga karena perbedaan cuaca dan topografi daerah yang lebih kering dan panas. Tingginya tingkat infeksi cacing Nematoda yang dipoeroleh juga tetap lebih tinggi dibandingkan dengan penelitian lain di Sulawesi dengan tingkat infeksi Nematoda sebesar 75\% (Hutauruk et al., 
2009) dan di Aceh sebesar 66\% (Zulfikar et al., 2012),

Tingkat infeksi cacing trematoda pada penelitian ini sedikit lebih tinggi dibandingkan temuan kasus yang sama di Surabaya (Wibisono dan Solfaine, 2016), sebesar 10,8\% -- 28,1\%. Penelitian pembanding ini merupakan tingkat infeksi Nematoda dan Trematoda bukan pada kambing Boer. Tingkat infeksi cacing pada kambing Boer hingga saat ini belum ditemukan.
Pada kelompok kambing dewasa lebih banyak yang terinfeksi (Tabel 1), sedangkan berdasarkan rata-rata jumlah telur cacing dalam feses (telur tiap gram feses/TTG) maka kambing muda menunjukkan jumlah telur yang lebih banyak dibandingkan kambing yang lebih tua (TTG; $268>174$ dan 226,2). Gambaran tingkat infeksi Nematoda antar kelompok atau kategori kambing Boer dengan berbeda tingkatan umur menunjukkan perhitungan yang tidak berbeda nyata (Tabel 2).

Tabel 1. Tingkat infeksi cacing Nematoda pada ternak kambing Boer pada berbagai tingkatan umur.

\begin{tabular}{|c|c|c|c|c|}
\hline \multirow{2}{*}{ Umur } & \multicolumn{2}{|c|}{ Infeksi Nematoda } & \multirow{2}{*}{ Total } & \multirow{2}{*}{$\begin{array}{c}\text { Tingkat Infeksi } \\
(\%)\end{array}$} \\
\hline & Positif & Negatif & & \\
\hline Menyusui & 8 & 2 & 10 & 80 \\
\hline Lepas sapih & 10 & 0 & 10 & 100 \\
\hline Dewasa & 10 & 0 & 10 & 100 \\
\hline
\end{tabular}

Tabel 2. Hasil analisis Chi-Square tingkat infeksi cacing Nematoda pada ternak kambing Boer pada berbagai tingkatan umur

\begin{tabular}{lcccc}
\hline \multicolumn{1}{c}{ Umur } & Terinfeksi & $\begin{array}{c}\text { Tidak } \\
\text { Terinfeksi }\end{array}$ & $\mathbf{X}^{\mathbf{2}}$ & Lis is $\mathbf{X}^{\mathbf{2}}$ tabel \\
\hline Menyusui & 8 & 2 & 4,28 & 5,99 \\
Lepas sapih & 10 & 0 & & \\
Dewasa & 10 & 0 & & \\
\hline
\end{tabular}

Rute penularan infeksi cacing adalah melalui mulut (per os), dari pakan ternak atau rumput yang tercemar telur atau larva cacing. Tingginya tingkat infeksi pada kambing dewasa diduga karena secara kuantitatif pakan yang dimakan oleh kambing dewasa lebih banyak, sehingga mempunyai potensi terinfeksi cacing lebih besar dibandingkan kambing umur muda. Kemudian jika diamati dari tingginya jumlah telur cacing per gram feses/TTG pada kambing Boer muda dibandingkan dengan kambing Boer dewasa. Hal ini berkaitan dengan masalah imunitas, yaitu kambing dewasa akan mempunyai imunitas yang lebih baik sehingga dapat mengurangi jumlah infeksi cacing dalam pencernaanya yang berakibat pada penurunan kuantitas telur cacing yang ditemukan.

Hasil analisis Chi-Square yang tidak berbeda nyata pada nematodiasis kambing Boer, diduga disebabkan terdapatnya model manajemen yang sama antara tiga kategori umur kambing, yaitu ternak disatukan dalam satu kandang yang sama sehingga memungkinkan terjadinya penularan antar kelompok bahkan memicu terjadinya infeksi cacing ulang.

Infeksi Trematoda memerlukan induk semang antara (hospes intermedier), yaitu siput Lymnea sp. untuk menyempurnakan siklus hidupnya, tanpa adanya siput tersebut cacing tidak dapat melanjutkan siklus hidupnya untuk menginfeksi hewan atau manusia (Levine, 1995). Tingginya tingkat infeksi pada kambing menyusui diduga lebih berkaitaan dengan masalah imunitas seperti pada kasus infeksi cacing Nematoda (Tabel $3)$.

Tabel 3. Tingkat infeksi cacing Trematoda pada ternak kambing Boer pada berbagai tingkatan umur.

\begin{tabular}{lcccc}
\hline \multicolumn{1}{c}{ Umur } & \multicolumn{2}{c}{ Infeksi Trematoda } & Total & $\begin{array}{c}\text { Tingkat Infeksi } \\
(\boldsymbol{\%})\end{array}$ \\
\hline Positif & Negatif & & 20 \\
Lenyusui & 2 & 8 & 10 & 10 \\
Dewasa & 1 & 9 & 10 & 10 \\
\hline
\end{tabular}


Tabel 4. Hasil analisis Chi-Square tingkat infeksi cacing Trematoda pada ternak kambing Boer pada berbagai tingkatan umur

\begin{tabular}{lcccc}
\hline \multicolumn{1}{c}{ Umur } & Terinfeksi & $\begin{array}{c}\text { Tidak } \\
\text { Terinfeksi }\end{array}$ & $\mathbf{X}^{\mathbf{2}}$ & Lis is $\mathbf{X}^{\mathbf{2}}$ tabel \\
\hline Menyusui & 2 & 8 & 0,577 & 5,99 \\
Lepas sapih & 1 & 9 & & \\
Dewasa & 1 & 9 & & \\
\hline
\end{tabular}

Pada infeksi cacing Trematoda yang dibedakan pada berbagai kelompok umur tidak terdapat perbedaan yang nyata (Tabel 4 ), tetapi pada umur paling muda menunjukkan tingkat infeksi yang paling tinggi $(6,67 \%)$. Dibandingkan hasil penelitian Wibisono dan Solfaine (2016), infeksi trematoda pada kambing Boer sebesar 10,8\% maka tingkat infeksi pada kambing Boer dalam penelitian ini masih lebih rendah. Tingkat infeksi cacing Trematoda yang rendah pada kambing Boer, berarti bahwa kambing Boer lebih tahan terhadap infeksi cacing Trematoda dibandingkan pada hewan ternak lain.

\section{SIMPULAN}

Kambing Boer pada peternakan di Desa Karangtengah, Kecamatan Baturaden, Kabupaten Banyumas, menunjukkan 93,33\% terinfeksi Nematoda dan 13,33\% terinfeksi Trematoda. Tingkat infeksi Nematoda dan Trematoda menunjukkan hasil yang berbeda, baik pada kelompok kambing yang sedang menyusui, lepas sapih dan dewasa.

\section{DAFTAR PUSTAKA}

Djuniadi, M. A. dan W. Lestari. 2014. Statistik Inferensial, Teori, Aplikasi dan Latihan Soal Dengan SPSS. PPS UNNES Semarang.

Hutauruk, J.D., D. Nuraeni, Purwanta dan S. Setiawaty. 2009. Identifikasi Cacing Saluran Pencernaan (Gastrointestinal) pada Sapi Bali
Melalui Pemeriksaan Tinja di Kabupaten Goa. J. Agrisistem. STPP Goa 5(1)10-12.

Indradji, M. and E. Yuwono. 2004. Grassing As Potential Factor in Gastrointestinal Nematodiasis in Goat in Banyumas District. animalproduction.net

Levine, N.D. 1995. Parasitologi Veteriner, diterjemahkan oleh S. Soekardono. GMU Press.

Mukti, T., I.B.M. Oka dan I.M. Dwinata. 2016. Prevalensi Cacing Nematoda Saluran Pencernaan pada Kambing Peranakan Ettawa di Kecamatan Siliragung, Kabupaten Banyuwangi, Jawa Timur. Indonesia Medicus Veterinus 5(4): 330-336.

Naseh, S. (1993). Lebih Lanjut Dengan Regresi Logistik. Media Litbangkes 3(1): 11-14.

Prastowo, J. dan Sumartono.1996. Dinamika Jumlah Larva Nematoda Pada Rumput Di Padang Penggembalaan. Bull. FKH UGM 15(12): 47-54.

Rianto, E.. 2004. Kandang Kambing. LPM UNDIP. Semarang.

Soulsby E.Y.L. 1982. Helminth, arthropods and protozoa of domesticated animals. 7ed. Williams and Wilkins. Baltimore.

Wibisono, F.J. dan R. Solfaine. 2016. Insiden Hewan Qurban sebagai Vektor Penular Penyakit Cacing Hati (Fasciolasis) di Surabaya. J. Kajian Vet. 3(2): 139-146

Zulfikar, Hambali dan Razali. 2012. Derajat Infestasi Parasit Nematoda Gastrointestinal pada Sapi di Aceh Bagian Tengah. Universitas Syah Kuala. Aceh 